\title{
Health promoting effects of fermented foods against cancer: an updated concise review
}

\author{
Periyanaina KESIKA ${ }^{1}$, Bhagavathi Sundaram SIVAMARUTHI ${ }^{1}$, Chaiyavat CHAIYASUT $^{1 *}(\mathbb{D}$
}

\begin{abstract}
The global cancer burden has increased, and about 9.6 million cancer-related deaths were recorded in 2018. Genetic makeup, unhealthy lifestyle, urbanization, obesity, and dietary preferences are key risk factors associated with cancer incidence and development. Next to lung cancer, colorectal cancer is the most perilous cancer type in terms of mortality rate. Diet plays a major role in colorectal cancer risk. The consumption of vegetables, unprocessed cereals, fish product, and fermented foods are associated with lower cancer risk, while raw and processed red meats and refined foods are associated with increased cancer risk. The anti-cancer properties of fermented foods and their possible mechanisms are summarized in this review. Some studies indicated that the consumption of fermented foods reduced the risk of cancer and improved the health status of cancer patients. However, some other research findings suggested that the intake of fermented foods was not associated with reduced cancer risk. Several signaling pathways (p38 MAPK, ERK1/2, energy deprivation, and death-receptor mediated pathways) are involved in the anti-proliferative and growth suppressive properties of fermented foods. Overall, the literature survey suggested that the consumption of fermented foods might reduce cancer risk and improve health status in association with other factors, such as genetics and healthy lifestyle.
\end{abstract}

Keywords: fermented foods; anticancer; apoptosis; inflammation; diet.

Practical Application: The manuscript summarizes the anti-cancer properties and possible mechanism of fermented foods, which highlights the benefits of fermented foods.

\section{Introduction}

Approximately half of the global burden of cancer cases occur in Asian countries. It has been projected that $~ 10.6$ million cancer cases may occur in 2030 (Sankaranarayanan et al., 2014). The incidence of cancer will increase due to urbanization, lifestyle changes (unhealthy lifestyle such as use of tobacco, alcohol consumption, and unhealthy diet), aging (one of the key factors of cancer), and socioeconomic development. The incidence and mortality rate of the ten most common cancers (the cancer types include lung, stomach, liver, colorectum, oesophagus, prostate, bladder, leukaemia, lip and oral cavity, and non-Hodgkin lymphoma in men; the cancer types include breast, cervix uteri, lung, stomach, colorectum, liver, corpus uteri, oesophagus, ovary, and leukaemia in women) will increase by the year 2030 (Sankaranarayanan et al., 2014).

Diet is one of the influential environmental factors associated with cancer risk. A proper dietary pattern may reduce the risk of cancer development (Vera-Ramirez et al., 2012); importantly, diet plays a critical role in breast cancer risk (Ewertz \& Gill, 1990; Sieri et al., 2008). The American Cancer Society proposed some nutritional guidelines (categorized as diet, physical activities, and weight management) for cancer prevention based on scientific evidence; the recommendations are also updated based on the recent scientific reports (Bail et al., 2016).

The systemic review and meta-analysis by Grosso et al. (2017) included studies $(\mathrm{n}=93)$ on the role of diet in cancer development and reported that proper dietary pattern reduced the risk of colon and breast cancers. Additionally, regular physical activity and weight control also reduced the risk of cancer (Grosso et al., 2017). A recent case-control study revealed that high consumption of meat product is associated with increased risk of breast cancer among Taiwanese women, while vegetarian diet reduced breast cancer risk (Chang et al., 2017). Similarly, the consumption of vegetables and seafood are greatly associated with reduced risk of breast cancer in Chinese women (Zhang et al., 2011) and Korean women (Cho et al., 2010).

Fermented foods (generally made by spontaneous or specific fermentation process mediated by bioactive microorganisms) are considered as one of the functional foods with a long history of use since human civilization. Fermented foods are made with almost all kind of food materials, including vegetables, legumes, starchy roots and tubers, milk, fish, and meat. The preparation methods and raw materials used vary based on tradition and availability, respectively (Sivamaruthi et al., 2018a). The consumption of fermented foods provides several health benefits (Sivamaruthi et al., 2018a; Kim et al., 2016; Marco et al., 2017; Sivamaruthi et al., 2018b). Chilton et al. (2015) suggested the inclusion of fermented foods in the food guides globally.

The current review focused on the anti-cancer property of fermented foods. The appropriate scientific evidences were collected from Scopus, PubMed, and Google Scholar, and 
the relevant papers were selected without any chronological restrictions and reviewed in the present manuscript.

\section{Anti-cancer property of fermented products}

The mechanism behind the anti-cancer activity of fermented foods varies depending on the type of food, phytochemical composition, type of fermentation, and microbial composition of the food. Induction of apoptosis, suppression of cell proliferation, cell cycle arrest and inhibition of inflammatory reaction are the most possible mechanisms by which fermented foods confer protective activity against cancer occurrence and development (Supplementary Material - Figure. S1). The supplementation of fermented foods protects healthy cells via improvement of anti-inflammation and antioxidant mechanisms (Figure. S2). The predominant outcomes of in vitro and in vivo studies on anti-cancer properties of fermented foods are listed in Table S1.

\subsection{In vitro studies}

Kim et al. (2003) studied the anti-cancer property of the solvent extracts of Manda Enzyme ${ }^{\star}$ (a fermented product) in vitro. Bioactivity varied among the extracts (the extracts of the fermented product were prepared by $55 \%$ ethanol extraction and then the concentrated supernatant was fractionated into chloroform, ethyl acetate, $\mathrm{n}$-hexane, methanol-insoluble and methanol-soluble extracts) and cell types. The $n$-hexane extract $(400 \mu \mathrm{g} / \mathrm{ml})$ showed high anti-proliferative activity against human rectal cancer cell line (HRT-18), human hepatoma cell line (HepG2), and human colon cancer cell line (HCT48). The results suggested that Manda Enzyme ${ }^{\oplus}$ has bioactive compounds with anti-cancer activity (Kim et al., 2003).

Horie et al. (2016) investigated the anti-cancer activity of Aspergillus oryzae-mediated fermented brown rice (FBRE) extract using human acute lymphoblastic leukemia cells (Jurkat cells). The aqueous extract of FBRE reduced the viability of human acute lymphoblastic leukemia cells in a concentration and time-dependent manner. FBRE induced the caspase- $8,-9$, and -3 cleavages and expression of death receptor-related proteins like membrane-targeted death ligand (truncated Bcl-2 Homology 3 interacting-domain death agonist, $\mathrm{tBid}$ ), death receptor-5 (DR5), and apoptosis antigen (Fas cell surface death receptor, Fas) and suppressed the apoptosis inhibitor (B-cell lymphoma 2, Bcl-2) expression in human acute lymphoblastic leukemia cells. The inhibitor based experiments showed that caspase- 8 inhibitor can prevent cellular toxicity. The results collectively revealed that FBRE could induce lymphoblastic leukemia cell death via death receptor and tBid-mediated pathways (Horie et al., 2016).

Lee et al. (2013) studied the cytotoxic activity, and anti-proliferative activity of extracts (ethanol extract and ethyl acetate extract) of Monascus purpureus-mediated fermented red mold rice (FRMR). The extracts of FRMR exhibited cytotoxic activity and anti-proliferative activity on human breast adenocarcinoma cells (MCF-7; BCRC60436). FRMR treatment stimulated apoptosis in MCF-7 cell, which was characterized by condensed chromatin and DNA fragmentation. FRMR treatment arrested the cell cycle at the G2/M phase in MCF-7 cells. Apoptosis might have occurred through mitochondrial-dependent pathway with the aid of activated caspase- 3 and 9 and the involvement of bax/bcl-2. The study suggested that FRMR has strong anti-cancer activity against human breast adenocarcinoma cell and could be used to prevent the development of breast cancer (Lee et al., 2013). FRMR could be used as a potential functional food for its health promoting property.

Koh et al. (2018) examined the anti-proliferative and protective effects of the aqueous and ethanol extracts of fermented wheat germ (FWG) using human ovarian cancer cell lines (SK-OV-3 and OVCAR-3) and natural killer cell line (NK-92), respectively. The ethanol extract of FWG significantly suppressed the growth and proliferation of cancer cell lines via activating caspase-3, 7, 9 and poly (ADP-ribose) polymerase cleavage. Ethanol extract of FWG also reduced NF- $\mathrm{KB}$ activity and reactive oxygen species (ROS) production in cancer cells. However, no such phenomena occurred in NK-92 cell line treated with ethanol extract of FWG. It was observed that the FWG-treated NK-92 cell lines secreted more Interferon-gamma (IFN- $\gamma$ ). The results suggested that FWG induced apoptosis in the ovarian cancer cells and enhanced the cytotoxicity of NK cells against cancer cells (Koh et al., 2018).

Borowicki et al. (2010) investigated the anti-cancer property of the fermented wheat aleurone (FWA) using HT29 cells. In vitro fermentation process increased the short chain fatty acids and ammonia content and reduced the bile acid content in wheat aleurone. The fermented wheat aleurone (FWA) exhibited potent anti-cancer activity in HT29 cells. The growth and proliferation of the cancer cell were significantly reduced in the FWA-treated group compared with the control group. Increased apoptosis and cell cycle arrest (at G0/G1 phase) were observed in the FWA-treated group. The results suggested that FWA could be a potent chemoprotective agent (Borowicki et al., 2010).

Kazimierczak et al. (2014) investigated the antioxidant levels and anticancer property of naturally fermented beetroot juices obtained from organically and conventionally grown beetroots. Naturally fermented beetroot juice induced necrosis and late apoptosis in AGS cells (Gastric adenocarcinoma cells). The efficacy of the bioactivity was higher in beetroots cultivated through organic farming compared with that of the conventional farming. Ultra-performance liquid chromatography-quadrupole time-of-flight-liquid chromatography - mass spectrometry (UPLC Q-TOF LC-MS) based metabolomic analysis suggested that the chemical composition of organic and conventional beetroots vary, and the fermented beetroot extracts (extracts obtained from fermented juice of organic or conventional beetroots) showed a distinguishable chemical property. The results suggested that the cultivation method greatly influence the chemical composition and bioactivity, especially anti-cancer activity of fermented beetroots (Kazimierczak et al., 2014).

The anti-cancer property of standard kimchi (standard ingredients includes brined Baechu cabbage, radish, red pepper powder, salt, anchovy juice, green onion, garlic, sugar and ginger) and enriched kimchi (standard ingredients (except anchovy juice) along with additional anticancer ingredients such as mustard leaf, mushroom, sea tangle juice, pear, Chinese pepper, and mistletoe extract) with different fermentation periods has been assessed by Kim et al. (2015) using HT-29 colon cancer cells. The results showed that the optimally ripened kimchi (fermentation 
duration: 4 days at $15^{\circ} \mathrm{C}$ ) exhibited a higher anti-proliferative activity against HT-29 cells compared with fresh (fermentation duration: 0 days) and over-ripened (fermentation duration: 10 days at $15^{\circ} \mathrm{C}$ ) kimchi. Moreover, optimally ripened enriched kimchi (OREK; with added anticancer-ingredients) showed a significantly higher anti-proliferative activity compared with standard kimchi recipe. OREK reduced the expression of $\mathrm{Bcl}-2$ and promoted the apoptosis of HT-29 cells via Bax, caspase-3 and 9. Further, OREK inhibited the expression of inflammatory mediators such as iNOS and COX-2, thereby suppressed the cancer progression. The results suggested that optimally ripened enriched kimchi exhibited a more potent anti-proliferative activity than regular fresh and over-ripened kimchi (Kim et al., 2015). Optimally ripened kimchi could be considered as a functional food and Kimchi prepared with added functional ingredients could enhance its health promoting properties.

Cabbage is one of the major ingredients of kimchi. Song et al. (2018a) investigated the anti-cancer activity of kimchi prepared using Amtak Baechu cabbage (ABK) and standard Baechu cabbage (SBK) and with two different salting methods such as brine solution (salt solution) treatment method (BS) or dry salt treatment method (DS). Samples of Kimchi prepared using Amtak Baechu cabbage (both ABK-BS and ABK-DS) significantly suppressed the proliferation of human pancreas (Capan-2) and liver (HepG2) cancer cells compared with the samples of Kimchi prepared using standard Baechu cabbage (both SBK-BS and SBK-DS). Cell proliferation-associated gene p21 level significantly increased after $\mathrm{ABK}$ (both $\mathrm{ABK}-\mathrm{BS}$ and $\mathrm{ABK}-\mathrm{DS}$ ) treatment in cancer cells than that of the SBK (both SBK-BS and SBK-DS) treatment. The Capan-2 cell was more vulnerable to ABK (both ABK-BS and ABK-DS) treatment compared with liver cancer cells. Also, ABK-BS treatment exhibited higher cytotoxic effects to cancer cells than that of the ABK-DS treatment. The results suggested that $A B K$ exhibited anti-cancer activity against both Capan-2 and HepG2 cells, and the use of Amtak Baechu cabbage and brine solution for making kimchi (ABK-BS) could improve the health beneficial effect of kimchi regarding its anti-cancer property (Song et al., 2018a).

Lai et al. (2013) investigated the effect of fermentation on the anti-proliferative activity of soymilk. Streptococcus thermophilus 14085 and Bifidobacterium infantis 14603 mediated co-fermentation of soymilk (FSM) improved its anti-proliferative activity against HT-29 and Caco-2 cells in a dose-dependent manner. FSM extract $(400 \mu \mathrm{g} / \mathrm{ml})$ prepared with $80 \%$ methanol extraction showed $57.74 \pm 4.50$ and $59.28 \pm 2.45 \%$ of proliferation of HT-29 and Caco- 2 cells, respectively, which was lower compared with the proliferation of respective cells treated with the extract of unfermented soymilk $(400 \mu \mathrm{g} / \mathrm{ml})$. The results suggested that the fermentation process improved the anti-proliferative activity of soymilk effectively (Lai et al., 2013).

Doenjang is one of the fermented soybean products of Korea. Seol et al. (2016) examined the beneficial effects of water extract of long-term fermented doenjang. Fermented doenjang extract showed high contents of bioactive compounds and exhibited anti-proliferative activity against human breast cancer cell lines (MCF-7 and SK-BR-3). The gene expression data showed that fermented doenjang extract decreased the protein level expression of proliferation-associated genes, such as p85, ERK, and AKT. The proliferation of non-cancer cell line (HEK-293 cells) was not suppressed by the fermented doenjang extract. The increased protein level expression of cell cycle arrest genes (p53, and p27), pro-apoptotic gene (Bid), and the suppression of apoptotic inhibitor gene $\left(\mathrm{Bcl}-\mathrm{X}_{\mathrm{L}}\right)$ and a gene involved in cell cycle progress (CyclinD1) were detected in fermented doenjang-treated breast cancer cells. The treatment of fermented doenjang extract increased osteoblast differentiation in MC3T3-E1 osteoblast cells and this bioactivity increased with the fermentation duration up to 3 years. Fermented doenjang extract inhibited the osteoclastic differentiation. The study proved that fermented doenjang extract was packed with anti-proliferative bioactive compounds that could be used to treat breast cancer and also exhibited bone metabolism bioactivity (Seol et al., 2016). Therefore, fermentation duration influences the quality of doenjang in terms of bioactivity and health benefits.

Lee et al. (2018) studied the effect of enzymatic-fermented Citrus unshiu peel extract (EFCPE) on the growth and migration of human pancreatic cancer cells in vitro using SNU-213 and Panc- 1 cells. EFCPE suppressed the growth and migration of SNU-213 and Panc- 1 cells. It was noted that EFCPE treatment does not affect the human umbilical vein endothelial cells' growth and migration. Caspase-3, MKK3/6, and p38 signaling pathways mediated anti-cancer activity of EFCPE was observed in Panc- 1 cells. The anti-cancer property of EFCPE was attributed to the presence of bioactive compounds, such as naringenin and hesperetin. The results showed that EFCPE could be a potent therapeutic agent against pancreatic cancer (Lee et al., 2018).

Mao et al. (2018) studied the functional properties of preserved duck eggs. Treatment of preserved duck egg (alkaline-fermented food) powder showed in vitro anti-cancer activity in Caco-2 cells. The treatment involving in vitro-gastrointestinal (GI) enzyme digestion of preserved duck egg induced the apoptosis of Caco- 2 cells via caspase- 3 activation. The results showed that preserved duck eggs could be used as a functional food to prevent the occurrence of cancer (Mao et al., 2018).

Insampaedok-san, made with several herbs, is a traditional herbal medicine of East Asian countries. The herbs used in the preparation of Insampaedok-san (IS) have been reported to have several health benefits including anti-cancer activities. Park \& Kim, (2018) investigated the anti-cancer property of aqueous extract of IS (AEIS) and its fermented (Lactobacillus casei-mediated fermentation) IS (FAEIS) using several cancer cell lines. The results suggested that FAEIS was toxic to colon cancer cell line SW620, while other cancer cells (breast, gastric and DLD-1 colon cancer cells) were not affected. The cytotoxicity of FAEIS was mediated by caspase- 3 and poly (ADP-ribose) polymerase cleavage in relation to SW620 cells. The results suggested that FAEIS could be used for the development of alternative or adjuvant therapy for cancer treatment (Park \& Kim, 2018).

Aqueous extract of commercially available fermented Houttuynia cordata (FHC) products showed anti-proliferative activity against HeLa, HCT116, and HT29 cells in a dose- and time-dependent manner, while no toxic effect was observed on non-cancer Vero cells. The results suggested that commercial 
FHC has anti-cancer constituents that could be used for the treatment of cancer (Senawong et al., 2014).

The supernatant of in vitro fermented (using artificial intestinal lumen fluid and feces inoculum from a healthy donor) raw and roasted walnuts (FWN) was examined for its anti-cancer property by Schlörmann et al. (2017). Treatment of FWN supernatant (FWNS) significantly induced the expression of catalase (CAT) and glutathione S-transferase theta 2 (GSTT2) in LT97 colon adenoma cells. FWNS treatment effectively suppressed the growth of cancer cells and also induced apoptosis in a dose- and time-dependent manner. FWNS reduced the risk of colon cancer development, indicating that mild roasting process does not affect the chemopreventive nature of the walnuts (Schlörmann et al., 2017).

\subsection{In vivo studies}

Kefir is a probiotic fermented milk product with several health benefits. Melo et al. (2018) studied the health beneficial effect of fermented kefir milk on azoxymethane (AOM)-induced $\mathrm{ACF}$ in BALB-c mice. The supplementation of $5 \mathrm{ml} / \mathrm{kg}$ of kefir for 8 weeks significantly suppressed the formation and size of AOM-induced ACF in BALB-c mice. The bioactivity of kefir greatly depends on its microbial composition, especially the presence of probiotic strains. Ultra-high temperature treated kefir milk enhanced the growth of L. acidophilus more compared with pasteurized kefir milk. The study suggested that ultra-high temperature treated kefir milk enhanced the growth of probiotic strains, and regular consumption of kefir could prevent the occurrence of colon cancer (Melo et al., 2018). The fermentation conditions, especially fermentation period, significantly influenced the anti-proliferative effect of kefir (Hatmal et al., 2018).

L. helveticus R389-mediated fermented milk (yogurt) suppressed tumor growth and altered the inflammatory system positively in experimental colon cancer model (de Moreno de Leblanc \& Perdigón, 2010). Narushima et al. (2010) evaluated the inhibitory effect of yogurt (containing Streptococcus thermophilus CRL807 and Lactobacillus delbrueckii subsp. bulgaricus 2038) on aberrant crypt foci (ACF) formation in 2-amino-1-methyl6-phenylimidazo $(4,5$-b) pyridine (PhIP)-treated F344 rats, and colorectal tumors in 1, 2-dimethylhydrazine (DMH)-treated rasH2 mice. Treatment with yogurt significantly reduced the formation of ACF and aberrant crypts in PhIP-treated F344 rats, and reduced the number of tumors in DMH-treated rasH2 mice. Consumption of probiotic yogurt might suppress tumor formation (Narushima et al., 2010). Similarly, the supplementation of yogurt containing S. thermophilus CRL807 and L. delbrueckii subsp. bulgaricus CRL864 effectively reduced chemically induced intestinal inflammation and tumor formation in $\mathrm{BALB} / \mathrm{c}$ mice. The intestinal damage score, the number of infiltrating cells, and the thickening of the muscle layer were significantly reduced in the yogurt-supplemented group compared with the control group (untreated group). A notable level of reduction in multiple plaque lesions was observed in the treatment group. The microbial translocation was hindered in the yogurt-supplemented group, and the cytokines levels were positively regulated. Therefore, yogurt containing CRL807 and CRL864 exhibited potent anti-inflammatory and anti-cancer activities (Del Carmen et al., 2016). Thus, yogurt containing CRL807 and CRL864 could be used as a functional food during the treatment for inflammatory bowel diseases and colon cancer.

The supplementation of $10 \%$ A. oryzae-mediated fermented brown rice (FBR)-containing diet suppressed the metastasis of cancer cells in mice inoculated with colon cancer (26-L5) cells. FBR treatment activated and induced the macrophages to produce IFN- $\gamma$ in response to lipopolysaccharide exposure. The results concluded that FBR effectively blocked the metastasis of 26-L5 cells and activated the antioxidant mechanism against cancer development (Sakurai et al., 2006). Similarly, supplementation of $10 \%$ FBR containing diet significantly suppressed the incidence and multiplicity of gastric proliferative lesions in $N$-methyl- $N$ 'nitro- $N$ nitrosoguanidine-induced gastric carcinogenesis in experimental rats (Tomita et al., 2008). Different concentrations ( 5 or 10\%) of fermented brown rice and rice bran (FBRRB) were supplemented for 15 weeks to transgenic rat bearing adenocarcinoma of the prostate, and the impact of FBRRB on the incidence and progress of cancer were studied by Kuno et al. (2016). Incidence of adenocarcinoma and progress of prostate carcinogenesis were significantly suppressed in experimental rats fed with FBRRB compared with those of the control. In addition, FBRRB treatment promoted apoptosis and suppressed cancer cell proliferation; it up-regulated Phospho-AMP-activated kinase a (Thr172) expression in the prostate. The results indicate that FBRRB could prevent prostate cancer and also control prostate cancer via energy deprivation-mediated pathways (Kuno et al., 2016). In addition, the supplementation of FBRRB for 26 weeks at a concentration of $10 \%$ in the diet significantly reduced the incidence of thymic malignant lymphoma in AKR/NSlc mice, and the study recommended that FBRRB could prevent the development of human lymphoma (Kuno et al., 2018).

A 12 -week supplementation of $10 \%$ of miso (a fermented product made from soybean, rice, oat, and wheat) in the diet suppressed the number of lung tumors and adenocarcinoma in diisopropanolnitrosamine-induced experimental cancer rat model. Long-term fermented ( 6 months) miso exhibited higher chemopreventive activity against chemically-induced lung cancer in the rat compared with short-term fermented (3-4 days) miso. The results revealed that the consumption of miso could offer protection against lung cancer development, and the level of protection is highly associated with the fermentation time of miso (Shiraki et al., 2003).

Ganjangs refers to fermented soybean and other legume-based sauce, commonly used in Korean cuisine. Song et al. (2018b) studied the anti-cancer activity of fermented soy sauce (FSS) and sesame sauce (FS) as well as that of acid-hydrolyzed soy sauce (ASS) using AOM and DSS-treated mice model. FSS and FS supplementation prevented AOM/DSS-induced colon damages and suppressed the carcinogenesis by nullifying the expression of TNF- $\alpha$, IFN- $\gamma$, IL-6, Interleukin-17 alpha (IL-17a), cyclooxygenase-2 (COX-2), and nitric oxide synthase (iNOS); also, the supplementation induced the expression of tumor suppressor gene p53. ASS treatment did not exhibit a strong anti-cancer activity compared with that of FSS and FS. Consumption of ganjangs could provide protection against 
cancer, and the protective effect of ganjangs depends on the composition (Song et al., 2018b).

Mao et al. (2018) studied the functional properties of preserved duck eggs. Supplementation of preserved egg powder significantly lowered the hepatic levels of low-density lipoprotein cholesterol/ high density lipoprotein cholesterol (LDL-C/HDL-C), triglycerides (TG), and total cholesterol (TC) and also significantly reduced cancer markers such as Tumor necrosis factor-alpha (TNF- $\alpha$ ) and Interleukin-6 (IL-6) in experimental rats. The study proved that preserved egg supplementation improved the lipid profile and suppressed inflammation in vivo indicating that preserved duck eggs could be used as a functional food to manage metabolic disorder (Mao et al., 2018).

Kinouchi et al. (2012) studied the effects of L. helveticus subsp. jugurti 416 and Enterococcus faecium CRL 183 mediated fermented soybean product (FSP), FSP enriched with isoflavones (FSPIF), and non-fermented soybean product (NFSP) on the development of murine breast adenocarcinoma in mice. The FSP intervention group showed significantly reduced tumor size compared with the groups supplemented with NFSP and FSPIF. The nitric oxide (NO) production and Interleukin-17 beta (IL-1 $\beta$ ) level were found to be low in the FSP intervention group, whereas the FSPIF supplemented group showed an elevated level of NO and IL-1 $\beta$. The results showed that FSP could suppress tumor development effectively compared with FSPIF and NFSP. The enhanced bioactivity of FSP was attributed to the presence of the bioactive strains, L. helveticus and E. faecium (Kinouchi et al., 2012).

Meju is generally a mixture of potent probiotic strains and soybean. It is used as a starter for the production of Korean fermented soybean products. Jeong et al. (2012) examined the chemoprotective effect of meju prepared with A. oryzae, Bacillus subtilis-SKm, and Lactococcus lactis-Gam in azoxymethane (AOM) and dextran sulfate sodium (DSS)-induced colorectal cancer mice model. Meju supplementation (for seven weeks) significantly reduced the formation of neoplasia and the expression of iNOS, COX-2, and serum pro-inflammatory cytokines. It was noted that meju supplementation decreased the expression of Bcl-2 while inducing the expression of tumor suppressor proteins p51 and p53 in the colon tissue of the experimental mice. The results suggested that meju could ameliorate the symptoms of colon cancer in vivo (Jeong et al., 2012).

EFCPE suppressed tumor growth and the migration of human pancreatic cancer cells in SNU-213 xenograft model. Caspase-3 and MKK3/6 and P38 signaling pathways mediated anti-cancer activity of EFCPE was observed in SNU-213 xenograft model. Thus, EFCPE could be used as a potent therapeutic agent against pancreatic cancers (Lee et al., 2018).

\subsection{Results of human studies}

Demidov et al. (2008) conducted a randomized, open-label, pilot, phase II clinical trial and revealed that supplementation of Avemar $^{\text {III }}$ (fermented wheat germ extract) during dacarbazine-based adjuvant chemotherapy improved the overall health status and reduced the mortality rate of high risk stage III skin melanoma patients. The mortality of the patients was $34.6 \%$ in the Avemar ${ }^{\mathrm{mu}}$ supplemented group, which was significantly lower compared with that of the control group (61.5\%). The experimental group showed a reduction in disease progress and improvement in overall health status. The study recommended that Avemar ${ }^{\text {tw }}$ could be included in adjuvant melanoma therapy (Demidov et al., 2008).

A case-control study was conducted by Sonoda et al. (2004) in Japan based on the relation between the diet and prostate cancer and suggested that the consumption of fermented soy product and fish greatly reduced the risk of development of prostate cancer. Consumption of vegetables, fruits and milk are not associated with cancer incidence (Sonoda et al., 2004). Similarly, another case-control study showed that the consumption of miso soup and other soya foods reduced the risk of occurrence of hepatocellular carcinoma in Japanese A-bomb survivors (Sharp et al., 2005). Recently, Barrubés et al. (2018) reported that high consumption of dairy products and low-fat milk is associated with a reduced risk of development of colorectal cancer in older Mediterranean individuals (Barrubés et al., 2018).

A recent cohort study revealed that the consumption of fermented food was not associated with stomach cancer prevention (Wada et al., 2015). A population-based cohort study involving 30,792 people residing in Takayama, Japan, revealed that the consumption of soy isoflavone mainly in the form of non-fermented soy based food reduced the incidence of stomach cancer. The initial food consumption survey was conducted in 1992, and then the information about cancer incidence was collected from regional population-based cancer registries in 2008. Six-hundred and seventy-eight people (237 women and 441 men) developed stomach cancer. The statistical analysis suggested that the consumption of fermented soy product is not associated with lower stomach cancer incidence. The consumption of soy isoflavone, via non-fermented soy foods, significantly protected the people from stomach cancer (Wada et al., 2015).

Based on the reviewed in vitro and in vivo studies, apoptotic cell death of experimental cells was triggered by FWG treatment (Koh et al., 2018), by FWNS treatment (Schlörmann et al., 2017), through the activation of death receptor-mediated pathway and tBid-mediated mitochondrial pathway by the FBRE treatment (Horie et al., 2016), mitochondrial-dependent pathway by FRMR treatment (Lee et al., 2013); suppression of cell proliferation by FRMR treatment (Lee et al., 2013), by FWG treatment (Koh et al., 2018), by FWA treatment (Borowicki et al., 2010) by treating with optimally ripened enriched kimchi (Kim et al., 2015), by fermented soymilk treatment (Lai et al., 2013), by treatment with fermented doenjang extract (Seol et al., 2016); cell cycle arrest by FRMR treatment (Lee et al., 2013), by FWA treatment (Borowicki et al., 2010); anti-cancer activity of EFCPE mediated by Caspase-3, MKK3/6, and p38 signaling pathways (Lee et al., 2018); and inhibition of inflammatory reaction by yogurt intake (Del Carmen et al., 2016) are the most possible mechanisms by which fermented foods confer protective activity against cancer occurrence and development. Based on the few clinical studies, consumption of fermented products such as fermented wheat germ extract (Demidov et al., 2008), fermented soy product (Sonoda et al., 2004; Sharp et al., 2005; Wada et al., 2015) improved the health status of the people. 


\section{Conclusion}

Currently, fermented foods have gained more attention in terms of their health support and disease-controlling ability. Though several in vitro and in vivo studies and some clinical studies suggested that the consumption of fermented foods reduced the risk of cancer, a recent study suggested that consumption of fermented foods is not strongly associated with reduced cancer risk. The health-promoting ability of fermented foods relies on the nutritional (phytochemicals, vitamins, minerals, etc.) and microbial (probiotics) composition of the foods, in addition to ethnicity and other lifestyle-associated factors of consumers. Generally, fermented foods rich in SCFA, ammonia, naringenin, hesperetin, and potent probiotics confer protection against cancer. The anti-cancer property of fermented foods does not depend on a single molecular pathway because of the compositional differences among the foods. The supplementation of fermented foods may exterminate cancer cells via apoptosis induction, inhibition of cell proliferation, and activation of tumor suppressor genes, and it may also protect healthy cells via improvement of anti-inflammation and antioxidant mechanisms. Several signaling pathways, such as death-receptor mediated pathway, tBid-mediated mitochondrial pathway (Horie et al., 2016; Lee et al., 2013), energy deprivation pathway (Kuno et al., 2016), ERK1/2 pathway, and p38 MAPK pathway (Lee et al., 2018), are associated with anti-cancer activities of fermented foods. Based on the reviewed literature, consumption of fermented foods might reduce cancer risk and improve health status. A recent meta-analysis study by Zhang et al. (2019) based on the relation between the intake of fermented dairy foods and overall cancer risk suggested that consumption of fermented dairy foods was associated with an overall reduced risk of cancer. Literature available based on the anti-cancer property of fermented foods is inadequate, especially with regards to the very limited clinical studies describing the association between fermented foods and cancer risk. Therefore, more clinical and cohort studies are required to figure out the role of fermented foods in human health and diseases, especially in non-communicable diseases like cancer.

\section{Acknowledgements}

We wish to thank Faculty of Pharmacy, Chiang Mai University, Chiang Mai, Thailand for the support. P.K. and B.S.S acknowledge the Chiang Mai University-Post-doc grant for the necessary support.

\section{References}

Bail, J., Meneses, K., \& Demark-Wahnefried, W. (2016). Nutritional status and diet in cancer prevention. Seminars in Oncology Nursing, 32(3), 206-214. http://dx.doi.org/10.1016/j.soncn.2016.05.004. PMid:27539277.

Barrubés, L., Babio, N., Mena-Sánchez, G., Toledo, E., Ramírez-Sabio, J. B., Estruch, R., Ros, E., Fitó, M., Arós, F., Fiol, M., Santos-Lozano, J. M., Serra-Majem, L., Pintó, X., Martínez-González, M. Á., Sorlí, J. V., Basora, J., \& Salas-Salvadó, J., and the PREvención con DIeta MEDiterránea Study Investigators (2018). Dairy product consumption and risk of colorectal cancer in an older mediterranean population at high cardiovascular risk. International Journal of Cancer, 143(6), 1356-1366. http://dx.doi.org/10.1002/ijc.31540. PMid:29663376.
Borowicki, A., Stein, K., Scharlau, D., Scheu, K., Brenner-Weiss, G., Obst, U., Hollmann, J., Lindhauer, M., Wachter, N., \& Glei, M. (2010). Fermented wheat aleurone inhibits growth and induces apoptosis in human HT29 colon adenocarcinoma cells. British Journal of Nutrition, 103(3), 360-369. http://dx.doi.org/10.1017/ S0007114509991899. PMid:19732471.

Chang, Y. J., Hou, Y. C., Chen, L. J., Wu, J. H., Wu, C. C., Chang, Y. J., \& Chung, K. P. (2017). Is vegetarian diet associated with a lower risk of breast cancer in Taiwanese women? BMC Public Health, 17(1), 800. http://dx.doi.org/10.1186/s12889-017-4819-1. PMid:29017525.

Chilton, S. N., Burton, J. P., \& Reid, G. (2015). Inclusion of fermented foods in food guides around the world. Nutrients, 7(1), 390-404. http://dx.doi.org/10.3390/nu7010390. PMid:25580813.

Cho, Y. A., Kim, J., Shin, A., Park, K. S., \& Ro, J. (2010). Dietary patterns and breast cancer risk in Korean women. Nutrition and Cancer, 62(8), 1161-1169. http://dx.doi.org/10.1080/01635581.2010.5146 60. PMid:21058205.

de Moreno de Leblanc, A., \& Perdigón, G. (2010). The application of probiotic fermented milks in cancer and intestinal inflammation. The Proceedings of the Nutrition Society, 69(3), 421-428. http://dx.doi. org/10.1017/S002966511000159X. PMid:20550747.

Del Carmen, S., de Moreno de LeBlanc, A., \& LeBlanc, J. G. (2016). Development of a potential probiotic yoghurt using selected antiinflammatory lactic acid bacteria for prevention of colitis and carcinogenesis in mice. Journal of Applied Microbiology, 121(3), 821-830. http://dx.doi.org/10.1111/jam.13213. PMid:27341191.

Demidov, L. V., Manziuk, L. V., Kharkevitch, G. Y., Pirogova, N. A., \& Artamonova, E. V. (2008). Adjuvant fermented wheat germ extract $\left(\right.$ Avemar $\left.^{\mathrm{nu}}\right)$ nutraceutical improves survival of high-risk skin melanoma patients: A randomized, pilot, phase ii clinical study with a 7-year follow-up. Cancer Biotherapy \& Radiopharmaceuticals, 23(4), 477-482. http://dx.doi.org/10.1089/cbr.2008.0486. PMid:18771352.

Ewertz, M., \& Gill, C. (1990). Dietary factors and breast-cancer risk in Denmark. International Journal of Cancer, 46(5), 779-784. http:// dx.doi.org/10.1002/ijc.2910460505. PMid:2228305.

Grosso, G., Bella, F., Godos, J., Sciacca, S., Del Rio, D., Ray, S., Galvano, F., \& Giovannucci, E. L. (2017). Possible role of diet in cancer: systematic review and multiple meta-analyses of dietary patterns, lifestyle factors, and cancer risk. Nutrition Reviews, 75(6), 405-419. http://dx.doi.org/10.1093/nutrit/nux012. PMid:28969358.

Hatmal, M. M., Nuirat, A., Zihlif, M. A., \& Taha, M. O. (2018). Exploring the influence of culture conditions on kefir's anticancer properties. Journal of Dairy Science, 101(5), 3771-3777. http://dx.doi.org/10.3168/ jds.2017-13539. PMid:29501341.

Horie, Y., Nemoto, H., Itoh, M., Kosaka, H., \& Morita, K. (2016). Fermented brown rice extract causes apoptotic death of human acute lymphoblastic leukemia cells via death receptor pathway. Applied Biochemistry and Biotechnology, 178(8), 1599-1611. http://dx.doi. org/10.1007/s12010-015-1970-y. PMid:26769704.

Jeong, J. K., Chang, H. K., \& Park, K. Y. (2012). Inhibitory effects of meju prepared with mixed starter cultures on azoxymethane and dextran sulfate sodium-induced colon carcinogenesis in mice. Journal of Carcinogenesis, 11(1), 13. http://dx.doi.org/10.4103/14773163.100404. PMid:23230391.

Kazimierczak, R., Hallmann, E., Lipowski, J., Drela, N., Kowalik, A., Püssa, T., Matt, D., Luik, A., Gozdowski, D., \& Rembiałkowska, E. (2014). Beetroot (Beta vulgaris L.) and naturally fermented beetroot juices from organic and conventional production: metabolomics, antioxidant levels and anticancer activity. Journal of the Science of Food and Agriculture, 94(13), 2618-2629. http://dx.doi.org/10.1002/ jsfa.6722. PMid:24798659. 
Kim, B., Hong, V. M., Yang, J., Hyun, H., Im, J. J., Hwang, J., Yoon, S., \& Kim, J. E. (2016). A review of fermented foods with beneficial effects on brain and cognitive function. Preventive Nutrition and Food Science, 21(4), 297-309. http://dx.doi.org/10.3746/pnf.2016.21.4.297. PMid:28078251.

Kim, B., Song, J. L., Ju, J. H., Kang, S. A., \& Park, K. Y. (2015). Anticancer effects of kimchi fermented for different times and with added ingredients in human HT-29 colon cancer cells. Food Science and Biotechnology, 24(2), 629-633. http://dx.doi.org/10.1007/s10068015-0082-3.

Kim, D. C., Hwang, W. I., \& In, M. J. (2003). In vitro antioxidant and anticancer activities of extracts from a fermented food. Journal of Food Biochemistry, 27(6), 449-459. http://dx.doi.org/10.1111/j.1745-4514.2003. tb00593.x.

Kinouchi, F. L., Maia, D. C. G., de Abreu Ribeiro, L. C., Placeres, M. C. P., de Valdez, G. F., Colombo, L. L., Rossi, E. A., \& Carlos, I. Z. (2012). A soy-based product fermented by Enterococcus faecium and Lactobacillus helveticus inhibits the development of murine breast adenocarcinoma. Food and Chemical Toxicology, 50(11), 4144-4148. http://dx.doi.org/10.1016/j.fct.2012.08.038. PMid:22954488.

Koh, E. M., Lee, E. K., Song, J., Kim, S. J., Song, C. H., Seo, Y., Chae, C. H., \& Jung, K. J. (2018). Anticancer activity and mechanism of action of fermented wheat germ extract against ovarian cancer. Journal of Food Biochemistry, 42(6), e12688. http://dx.doi.org/10.1111/jfbc.12688.

Kuno, T., Kato, H., Naiki-Ito, A., Suzuki, S., Tanaka, T., Takahashi, S., \& Mori, H. (2018). Preventive effects of fermented brown rice and rice bran on spontaneous lymphomagenesis in AKR/NSlc female mice. Asian Pacific Journal of Cancer Prevention, 19(11), 3217-3223. http://dx.doi.org/10.31557/APJCP.2018.19.11.3217. PMid:30486615.

Kuno, T., Nagano, A., Mori, Y., Kato, H., Nagayasu, Y., Naiki-Ito, A., Suzuki, S., Mori, H., \& Takahashi, S. (2016). Preventive effects of fermented brown rice and rice bran against prostate carcinogenesis in TRAP Rats. Nutrients, 8(7), 421. http://dx.doi.org/10.3390/ nu8070421. PMid:27409632.

Lai, L. R., Hsieh, S. C., Huang, H. Y., \& Chou, C. C. (2013). Effect of lactic fermentation on the total phenolic, saponin and phytic acid contents as well as anti-colon cancer cell proliferation activity of soymilk. Journal of Bioscience and Bioengineering, 115(5), 552-556. http://dx.doi.org/10.1016/j.jbiosc.2012.11.022. PMid:23290992.

Lee, C. I., Lee, C. L., Hwang, J. F., Lee, Y. H., \& Wang, J. J. (2013). Monascus-fermented red mold rice exhibits cytotoxic effect and induces apoptosis on human breast cancer cells. Applied Microbiology and Biotechnology, 97(3), 1269-1278. http://dx.doi.org/10.1007/ s00253-012-4279-6. PMid:22814414.

Lee, J., Lee, J., Kim, M., \& Kim, J. H. (2018). Fermented extraction of Citrus unshiu peel inhibits viability and migration of human pancreatic cancers. Journal of Medicinal Food, 21(1), 5-12. http:// dx.doi.org/10.1089/jmf.2017.3984. PMid:29346059.

Mao, C., Yu, Z., Li, C., Jin, Y., \& Ma, M. (2018). The functional properties of preserved eggs: from anti-cancer and anti-inflammatory aspects. Han-gug Chugsan Sigpum Hag-hoeji, 38(3), 615-628. PMid:30018504.

Marco, M. L., Heeney, D., Binda, S., Cifelli, C. J., Cotter, P. D., Foligné, B., Gänzle, M., Kort, R., Pasin, G., Pihlanto, A., Smid, E. J., \& Hutkins, R. (2017). Health benefits of fermented foods: microbiota and beyond. Current Opinion in Biotechnology, 44, 94-102. http://dx.doi. org/10.1016/j.copbio.2016.11.010. PMid:27998788.

Melo, A. F. P., Mendonça, M. C. P., \& Rosa-Castro, R. M. (2018). The protective effects of fermented kefir milk on azoxymethane-induced aberrant crypt formation in mice colon. Tissue \& Cell, 52, 51-56. http://dx.doi.org/10.1016/j.tice.2018.03.013. PMid:29857828.
Narushima, S., Sakata, T., Hioki, K., Itoh, T., Nomura, T., \& Itoh, K. (2010). Inhibitory effect of yogurt on aberrant crypt foci formation in the rat colon and colorectal tumorigenesis in $\mathrm{RasH} 2$ mice. Experimental Animals, 59(4), 487-494. http://dx.doi.org/10.1538/ expanim.59.487. PMid:20660995.

Park, H., \& Kim, K. D. (2018). Anticancer effect of fermented Insampaedoksan in human colon cancer cells: a pilot study. Molecular Biology Reports, 45(3), 373-377. http://dx.doi.org/10.1007/s11033-0184171-2. PMid:29611024.

Sakurai, H., Choo, M. K., Chino, A., Tega, E., Iwasaki, T., Kobayashi, H., \& Saiki, I. (2006). Antimetastatic and immunostimulatory properties of fermented brown rice. Journal of Traditional Medicines, 23, 112-116.

Sankaranarayanan, R., Ramadas, K., \& Qiao, Y. L. (2014). Managing the changing burden of cancer in Asia. BMC Medicine, 12(1), 3. http:// dx.doi.org/10.1186/1741-7015-12-3. PMid:24400922.

Schlörmann, W., Lamberty, J., Ludwig, D., Lorkowski, S., \& Glei, M. (2017). In vitro-fermented raw and roasted walnuts induce expression of CAT and GSTT2 genes, growth inhibition, and apoptosis in LT97 colon adenoma cells. Nutrition Research (New York, N.Y.), 47, 72-80. http://dx.doi.org/10.1016/j.nutres.2017.09.004. PMid:29241580.

Senawong, T., Khaopha, S., Misuna, S., Komaikul, J., Senawong, G., Wongphakham, P., \& Yunchalard, S. (2014). Phenolic acid composition and anticancer activity against human cancer cell lines of the commercially available fermentation products of Houttuynia cordata. ScienceAsia, 40(6), 420-427. http://dx.doi.org/10.2306/ scienceasia1513-1874.2014.40.420.

Seol, J. Y., Youn, Y. N., Koo, M., Kim, H. J., \& Choi, S. Y. (2016). Influence of water-soluble extracts of long-term fermented Doenjang on bone metabolism bioactivity and breast cancer suppression. Food Science and Biotechnology, 25(2), 517-524. http://dx.doi.org/10.1007/s10068016-0072-0. PMid:30263300.

Sharp, G. B., Lagarde, F., Mizuno, T., Sauvaget, C., Fukuhara, T., Allen, N., Suzuki, G., \& Tokuoka, S. (2005). Relationship of hepatocellular carcinoma to soya food consumption: a cohort-based, case-control study in Japan. International Journal of Cancer, 115(2), 290-295. http://dx.doi.org/10.1002/ijc.20897. PMid:15688396.

Shiraki, K., Une, K., Yano, R., Otani, S., Mimeoka, A., \& Watanabe, H. (2003). Inhibition by long-term fermented miso of induction of pulmonary adenocarcinoma by diisopropanolnitrosamine in wistar rats. Hiroshima Journal of Medical Sciences, 52(1), 9-13. PMid:12701648.

Sieri, S., Krogh, V., Ferrari, P., Berrino, F., Pala, V., Thiebaut, A. C., Tjønneland, A., Olsen, A., Overvad, K., Jakobsen, M. U., ClavelChapelon, F., Chajes, V., Boutron-Ruault, M. C., Kaaks, R., Linseisen, J., Boeing, H., Nöthlings, U., Trichopoulou, A., Naska, A., Lagiou, P., Panico, S., Palli, D., Vineis, P., Tumino, R., Lund, E., Kumle, M., Skeie, G., González, C. A., Ardanaz, E., Amiano, P., Tormo, M. J., MartínezGarcía, C., Quirós, J. R., Berglund, G., Gullberg, B., Hallmans, G., Lenner, P., Bueno-de-Mesquita, H. B., van Duijnhoven, F. J., Peeters, P. H., van Gils, C. H., Key, T. J., Crowe, F. L., Bingham, S., Khaw, K. T., Rinaldi, S., Slimani, N., Jenab, M., Norat, T., \& Riboli, E. (2008). Dietary fat and breast cancer risk in the European prospective investigation into cancer and nutrition. The American Journal of Clinical Nutrition, 88(5), 1304-1312. PMid:18996867.

Sivamaruthi, B. S., Kesika, P., \& Chaiyasut, C. (2018a). Impact of fermented foods on human cognitive function-A review of outcome of clinical trials. Scientia Pharmaceutica, 86(2), 22. http://dx.doi. org/10.3390/scipharm86020022. PMid:29857528. 
Sivamaruthi, B. S., Kesika, P., Prasanth, M. I., \& Chaiyasut, C. (2018b). A mini review on antidiabetic properties of fermented foods. Nutrients, 10(12), 1973. http://dx.doi.org/10.3390/nu10121973. PMid:30551623.

Song, G. H., Park, E. S., Lee, S. M., Park, D. B., \& Park, K. Y. (2018a). Beneficial outcomes of kimchi prepared with Amtak Baechu cabbage and salting in brine solution: Anticancer effects in pancreatic and hepatic cancer cells. Journal of Environmental Pathology, Toxicology and Oncology, 37(2), 151-161. http://dx.doi.org/10.1615/ JEnvironPatholToxicolOncol.2018026204. PMid:30055550.

Song, J. L., Choi, J. H., Seo, J. H., \& Park, K. Y. (2018b). Fermented ganjangs (soy sauce and sesame sauce) attenuates colonic carcinogenesis in azoxymethane/dextran sodium sulfate-treated C57BL/6J mice. Journal of Medicinal Food, 21(9), 905-914. http://dx.doi.org/10.1089/ jmf.2017.4111. PMid:30096014.

Sonoda, T., Nagata, Y., Mori, M., Miyanaga, N., Takashima, N., Okumura, K., Goto, K., Naito, S., Fujimoto, K., Hirao, Y., Takahashi, A., Tsukamoto, T., Fujioka, T., \& Akaza, H. (2004). A case-control study of diet and prostate cancer in Japan: possible protective effect of traditional Japanese diet. Cancer Science, 95(3), 238-242. http://dx.doi.org/10.1111/j.1349-7006.2004. tb02209.x. PMid:15016323.

Tomita, H., Kuno, T., Yamada, Y., Oyama, T., Asano, N., Miyazaki, Y., Baba, S., Taguchi, A., Hara, A., Iwasaki, T., Kobayashi, H., \& Mori,
H. (2008). Preventive effect of fermented brown rice and rice bran on N-methyl-N'-nitro-N-nitrosoguanidine-induced gastric carcinogenesis in rats. Oncology Reports, 19(1), 11-15. http://dx.doi. org/10.3892/or.19.1.11. PMid:18097570.

Vera-Ramirez, L., Ramirez-Tortosa, M. C., Sanchez-Rovira, P., RamirezTortosa, C. L., Granados-Principal, S., Lorente, J. A., \& Quiles, J. L. (2012). Impact of diet on breast cancer risk: a review of experimental and observational studies. Critical Reviews in Food Science and Nutrition, 53(1), 49-75. http://dx.doi.org/10.1080/10408398.2010 .521600. PMid:23035920.

Wada, K., Tsuji, M., Tamura, T., Konishi, K., Kawachi, T., Hori, A., Tanabashi, S., Matsushita, S., Tokimitsu, N., \& Nagata, C. (2015). Soy isoflavone intake and stomach cancer risk in Japan: From the Takayama study. International Journal of Cancer, 137(4), 885-892. http://dx.doi.org/10.1002/ijc.29437. PMid:25639758.

Zhang, C. X., Ho, S. C., Fu, J. H., Cheng, S. Z., Chen, Y. M., \& Lin, F. Y. (2011). Dietary patterns and breast cancer risk among Chinese women. Cancer Causes \& Control, 22(1), 115-124. http://dx.doi. org/10.1007/s10552-010-9681-8. PMid:21080051.

Zhang, K., Dai, H., Liang, W., Zhang, L., \& Deng, Z. (2019). Fermented dairy foods intake and risk of cancer. International Journal of Cancer, 144(9), 2099-2108. http://dx.doi.org/10.1002/ijc.31959. PMid:30374967. 


\section{Supplementary Material}

Supplementary material accompanies this paper.

Table S1. A list of reported anticancer activities of fermented foods.

Figure S1. The possible mechanism of anti-cancer activity of fermented foods via inducing the apoptosis of cancer cells. p53: Tumor protein p53; p21: Cyclin dependent kinase inhibitor 1A; Bcl-2: B-cell lymphoma 2; BAX: Bcl-2-associated X protein; tBid: truncated BH3 (Bcl-2 Homology 3) interacting-domain death agonist; Fas: Fas cell surface death receptor; ADP-ribose: Adenosine diphosphate-ribose; DR-5: Death receptor-5.

Figure S2. The possible protective mechanism of fermented foods on normal calls via suppressing the inflammatory response and improve the antioxidant mechanism. IL-10: Interleukin-10; IL-6: Interleukin-6; iNOS: Nitric oxide synthase; COX-2: Cyclooxygenase-2; TNF- $\alpha$ : Tumor necrosis factor-alpha; IFN- $\gamma$ : Interferon-gamma; CAT: Catalase; GSTT2: Glutathione S-transferase theta 2.

This material is available as part of the online article from http://www.scielo.br/CTA 